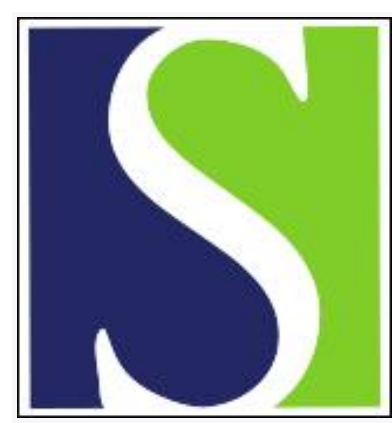

Scand J Work Environ Health 1988;14(2):91-94

https://doi.org/10.5271/sjweh.1942

Issue date: Apr 1988

Effects of exposure to Freon 11, 1,1,1-trichloroethane or perchloroethylene on the lipid and fatty-acid composition of rat cerebral cortex.

by Kyrklund T, Kjellstrand P, Haglid KG

Affiliation: Institute of Neurobiology, University of Goteborg, Sweden.

This article in PubMed: www.ncbi.nlm.nih.gov/pubmed/3387963

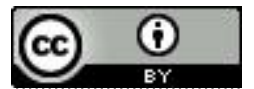




\title{
Effects of exposure to Freon 11, 1,1,1-trichloroethane or perchloroethylene on the lipid and fatty-acid composition of rat cerebral cortex
}

\author{
by Titus Kyrklund, PhD, ${ }^{1}$ Per Kjellstrand, $\mathrm{PhD},{ }^{2}$ Kenneth G Haglid, MD, $\mathrm{PhD}^{1}$
}

\begin{abstract}
KYRKLUND T, KJELLSTRAND P, HAGLID KG. Effects of exposure to Freon 11, 1,1,1-trichloroethane or perchloroethylene on the lipid and fatty-acid composition of rat cerebral cortex. Scand $J$ Work Environ Health 14 (1988) 91-94. Organic solvents are often present as mixtures in various industrial and household products. The adverse effects arising from exposure to these solvents have often been generalized to concern the whole group of solvents. In an examination of the possibility that organic solvents have general effects on experimental animals, rats were continuously exposed to vapors of the halogenated solvents Freon 11, perchloroethylene, and 1,1,1-trichloroethane. The lipid composition and fatty-acid pattern of ethanolamine phosphoglyceride from the cerebral cortex were analyzed. It was observed that only perchloroethylene had effects on the brain lipid composition. Cholesterol and total phospholipids were slightly reduced. Among the fatty acids the proportion of stearic acid was reduced and those of docosapentanoic, $22: 5(\mathrm{~N}=6)$, and of docosahexanoic, $22: 6(\mathrm{~N}=3)$, acids were increased. The changes in the fatty-acid pattern indicate that an alteration occurs in the desaturation of fatty acids. It seems probable that the chloroethylenes have specific effects on the fatty-acid pattern of brain phospholipids not shared by other solvents.
\end{abstract}

Key terms: acyl group composition, brain lipids, chronic solvent exposure, neurotoxicity, organic solvents, solvent toxicity.

The biological effects of organic solvents and related compounds on the nervous system are of great interest due to their widespread use in industrial and household products. Long-term exposures have been suspected to result in a solvent-related "psychoorganic syndrome."

In a series of papers $(10,11,12,14)$ we have reported the effects of chlorinated ethylenes, trichloroethylene, and perchloroethylene on the lipid composition of the brain and, in particular, on the fatty-acid pattern of ethanolamine phosphoglyceride (EPG). We observed that the fatty-acid pattern of EPG was changed among the most polyunsaturated fatty acids (PUFA), particularly in the regions rich in gray matter, such as the cerebral cortex and the hippocampus. These changes were characterized by a relative increase in the linoleic acid-derived ( $N-6$ ) PUFA, and a decrease in the linolenic acid-derived (N-3) PUFA. Both gerbils and rats were studied at various durations of exposure to trichloroethylene. Significant alterations appeared after $30 \mathrm{~d}$ of continuous exposure to $320 \mathrm{ppm}$. Since continuous exposure to organic solvents for $30 \mathrm{~d}$ at moderate concentrations seems to be a sufficient time to detect early changes in brain lipids, we chose this exposure for the screening of three commonly used, poorly metabolized halogenated solvents, ie, perchloro-

\footnotetext{
1 Institute of Neurobiology, University of Göteborg, Göteborg, Sweden.

2 Gambro AB, Lund, Sweden.
}

Reprint requests to: Dr T Kyrklund, Institute of Neurobiology, PO Box 33031, S-400 33 Göteborg, Sweden. ethylene (PCE), 1,1,1-trichloroethane (1,1,1-TCE), and Freon 11, in the present study. We had studied PCE previously $(10,14)$, but only in the gerbil and for much longer exposure times. The other two solvents have never previously been studied with respect to their effects on brain membrane lipids. The gross lipid composition and the fatty-acid pattern of EPG were studied in the cerebral cortex of animals exposed continuously for $30 \mathrm{~d}$ to PCE, 1,1,1-TCE, or Freon 11.

\section{Materials and methods}

Separate experiments were performed, one for each of the solvents. Male Sprague-Dawley rats were used (Anticimex AB, Sweden). Animal-weight means at the beginning of the experiments were as follows: PCE controls $196 \mathrm{~g}$, PCE-exposed $197 \mathrm{~g}$; 1,1,1-TCE controls $210 \mathrm{~g}, 1,1,1-\mathrm{TCE}$-exposed 208; Freon 11 controls $269 \mathrm{~g}$, Freon 11-exposed $270 \mathrm{~g}$. The animals were housed in plastic cages placed inside the inhalation chambers during the exposure period. Commercial laboratory rat chow (Ewos, Sweden) and water were freely available.

The exposure equipment has been described in detail previously (8). PCE or 1,1,1-TCE (Uddeholm, Sweden) was mixed with air $(2200 \mathrm{l} / \mathrm{h})$ to the desired concentration of $320 \mathrm{ppm}$; for Freon 11 (Imperial Chemical Industries, Great Britain) the concentration used was $580 \mathrm{ppm}$. Animals were continuously exposed for $30 \mathrm{~d}$ and each exposed group was matched by a control group that was housed in an identical chamber and exposed to air throughout the experimental 
period. At the end of the experiment the animals were immediately decapitated as they were brought from the exposure chambers.

After decapitation the brains were rapidly removed from the skulls and the cerebral cortex was dissected out. The dissected specimens were weighed, folded in aluminum foil, and then individually frozen on dry ice to be used later for the lipid determination.

Only the right cerebral cortex was analyzed. The tissue was homogenized in a glass homogenizer in $2 \mathrm{ml}$ of methanol at $0^{\circ} \mathrm{C}$, and $1 \mathrm{ml}$ of chloroform was added during the homogenization. The homogenate was centrifuged at $1000 \mathrm{~g}$ for $10 \mathrm{~min}$ in the homogenizers and reextracted by the aforementioned procedure.

The crude lipid extract was purified from nonlipid contaminants by a reversed-phase column method (9). To $6 \mathrm{ml}$ of the crude extract $8 \mathrm{ml}$ of methanol/water $(1: 1)$ was added and mixed to homogeneity. The entire mixture was poured onto a 3-ml C-18 "Bond Elut" column (Analytichem International, California, United States) equipped with a 50-ml reservoir. Column elution was carried out under a constant gentle vacuum with an elution speed of $1-2 \mathrm{ml} / \mathrm{min}$. Another $8 \mathrm{ml}$ of methanol/water $(1: 1)$ was added to the eluate, mixed, and again passed through the column. The resulting eluate was once again mixed with $8 \mathrm{ml}$ of methanol/water and passed through the column, as before. This last eluate was discarded before elution of the bound lipids. A 5-ml container was mounted on top of the columns, and the lipids were eluted at a moderate rate with two portions of $4.0-\mathrm{ml}$ chloroform/methanol $(1: 2)$. This final eluate was used directly for quantitative analyses of phospholipids and cholesterol.

Cholesterol was analyzed with a colorimetric method (4), and lipid phosphorous was measured according to Bartlett (3). The EPG fraction was isolated by thinlayer chromatography (TLC). The bands corresponding to $1.5 \mu \mathrm{mol}$ of phospholipids were applied to 0.25 -mm TLC plates (Merck, Federal Republic of Ger- many) that were developed unidirectionally in chloroform/methanol/water $(65: 25: 4)$. The lipid bands were visualized by a spray application of a bromphenol blue reagent to the TLC plate (15). The lipid bands corresponding to the EPG fraction were scraped into tubes with a teflon-lined screw cap. Fatty-acid methyl esters were prepared by transmethylation with sodium methylate in methanol at $37^{\circ} \mathrm{C}$ for $1 \mathrm{~h} \mathrm{(15).} \mathrm{The} \mathrm{methyl}$ esters were extracted in petroleum ether and analyzed by gas chromatography on a 2-m glass column packed with $10 \%$ DEGS-PS on Supelcoport ${ }^{\left(\text {(t) }^{\prime}\right.}$ (Supelco Inc, Pennsylvania, United States).

A statistical evaluation with Student's t-test was used to compare the exposed groups with their appropriate control animals.

\section{Results}

No changes in body or brain weight or changes in the cerebral cortex lipid or fatty-acid composition were observed after exposure to either 1,1,1-TCE or Freon 11. However exposure to PCE affected both the tissue weight and the brain lipid composition. The brain-tobody weight ratio was slightly decreased after the exposure [PCE controls $5.02 \cdot 10^{-3}\left(\mathrm{SD} 0.16 \cdot 10^{-3}\right) \mathrm{g}$, $\mathrm{N}=8$; PCE exposed $4.80 \cdot 10^{-3}$ (SD $\left.0.18 \cdot 10^{-3}\right) \mathrm{g}$, $\mathrm{N}=8 ; \mathrm{P}<0.05]$. The livers of the animals exposed to PCE were enlarged and their liver-to-body weight ratios were increased [PCE controls $3.40 \cdot 10^{-2}$ (SD $\left.0.267 \cdot 10^{-2}\right) \mathrm{g}, \mathrm{N}=8$; PCE-exposed $4.16 \cdot 10^{-2}(\mathrm{SD}$ $\left.\left.0.297 \cdot 10^{-2}\right) \mathrm{g}, \mathrm{N}=8 ; \mathrm{P}<0.001\right]$.

Both total cerebral phospholipids and cholesterol were slightly decreased after the exposure to PCE [phospholipids: PCE controls 80.1 (SD 2.54) $\mu \mathrm{mol} / \mathrm{g}$ wet weight (ww), PCE-exposed 77.3 (SD 1.23) $\mu \mathrm{mol} / \mathrm{g}$ ww, P<0.05; cholesterol: PCE controls 45.5 (SD 1.10) $\mu \mathrm{mol} / \mathrm{g} w \mathrm{w}, \mathrm{PCE}$-exposed 44.3 (SD 0.99) $\mu \mathrm{mol} / \mathrm{g}$ ww, $P<0.05)$. Changes in the fatty-acid pattern of EPG were also observed after exposure to PCE (table 1).

Table 1. Fatty acid composition of ethanolamine phosphoglyceride as the molar percentage in the cerebral cortex of rats exposed to perchloroethylene $(320 \mathrm{ppm}), 1,1,1$-trichloroethane $(320 \mathrm{ppm})$, or Freon $11(580 \mathrm{ppm})$ continuously for $30 \mathrm{~d}$.

\begin{tabular}{|c|c|c|c|c|c|c|c|c|c|c|c|c|}
\hline \multirow{3}{*}{ Fatty acid } & \multicolumn{4}{|c|}{ Perchloroethylene } & \multicolumn{4}{|c|}{ 1,1,1-trichloroethylene } & \multicolumn{4}{|c|}{ Freon 11} \\
\hline & \multicolumn{2}{|c|}{ Control group } & \multicolumn{2}{|c|}{ Exposed group } & \multicolumn{2}{|c|}{ Control group } & \multicolumn{2}{|c|}{ Exposed group } & \multicolumn{2}{|c|}{ Control group } & \multicolumn{2}{|c|}{ Exposed group } \\
\hline & Mean & SD & Mean & $\mathrm{SD}$ & Mean & $\mathrm{SD}$ & Mean & SD & Mean & $\mathrm{SD}$ & Mean & SD \\
\hline $16: 0$ & 7.30 & 0.31 & 7.46 & 0.43 & 7.42 & 0.24 & 7.45 & 0.23 & 6.64 & 0.15 & 6.80 & 0.13 \\
\hline $16: 1$ & 0.09 & 0.01 & 0.10 & 0.02 & 0.08 & 0.02 & 0.09 & 0.02 & 0.14 & 0.01 & 0.15 & 0.01 \\
\hline $18: 0$ & 25.5 & 0.59 & 24.4 & $0.68^{\star}$ & 26.3 & 0.98 & 26.0 & 1.05 & 23.9 & 0.67 & 23.8 & 0.55 \\
\hline $18: 1$ & 19.3 & 0,68 & 18.6 & 0.71 & 18.1 & 0.93 & 18.8 & 1.10 & 19.6 & 0.95 & 19.8 & 0.58 \\
\hline $18: 2(N-6)$ & 0.29 & 0.02 & 0.28 & 0.03 & 0.30 & 0.02 & 0.31 & 0.03 & 0.28 & 0.02 & 0.26 & 0.01 \\
\hline $20: 0$ & 0.18 & 0.04 & 0.16 & 0.04 & 0.16 & 0.02 & 0.13 & 0.02 & 0.19 & 0.02 & 0.20 & 0.02 \\
\hline $20: 1$ & 1.78 & 0.17 & 1.70 & 0.18 & 1.63 & 0.14 & 1.64 & 0.16 & 2.00 & 0.18 & 1.99 & 0.15 \\
\hline $20: 3(N-9)$ & 0.12 & 0.03 & 0.11 & 0.04 & 0.10 & 0.03 & 0.08 & 0.01 & 0.15 & 0.01 & 0.13 & 0.02 \\
\hline $20: 3(\mathrm{~N}-6)$ & 0.49 & 0.04 & 0.48 & 0.06 & 0.45 & 0.03 & 0.44 & 0.03 & 0.54 & 0.05 & 0.49 & 0.02 \\
\hline $20: 4(\mathrm{~N}-6)$ & 14.0 & 0.53 & 13.9 & 0.37 & 14.1 & 0.46 & 13.8 & 0.54 & 14.9 & 0.61 & 14.8 & 0.47 \\
\hline $22: 4(N-6)$ & 4.98 & 0.22 & 5.26 & 0.36 & 4.77 & 0.19 & 4.74 & 0.21 & 5.48 & 0.21 & 5.51 & 0.28 \\
\hline $22: 5(\mathrm{~N}-6)$ & 0.50 & 0.05 & 0.60 & $0.06^{*}$ & 0.48 & 0.05 & 0.47 & 0.05 & 0.52 & 0.08 & 0.56 & 0.06 \\
\hline $22: 5(\mathbf{N}-3)$ & 0.35 & 0.06 & 0.38 & 0.05 & 0.32 & 0.42 & 0.30 & 0.03 & 0.34 & 0.05 & 0.31 & 0.06 \\
\hline $22: 6(\mathrm{~N}-3)$ & 25.2 & 0.59 & 26.7 & $0.63^{* *}$ & 25.8 & 0.72 & 25.7 & 0.64 & 25.3 & 0.55 & 25.2 & 0.27 \\
\hline
\end{tabular}

* $\mathrm{P}<0.01$, "* $\mathrm{P}<0.001$ (in comparison with the respective control group). 
An increase among the long-chain PUFA 22:5 (N-6) and $22: 6(\mathrm{~N}-3)$ and a decrease in stearic acid were observed.

\section{Discussion}

Of the three solvents investigated (PCE, 1,1,1-TCE, and Freon 11), only PCE affected the tissue weights and the brain lipid and fatty-acid composition. In our previous report on PCE we found the whole-brain weights to be reduced in gerbils that where continuously exposed for $90 \mathrm{~d}$ at $320 \mathrm{ppm}$ (14). This observation was not reproduced in the present experiment exposing rats for $30 \mathrm{~d}$ to PCE. The small decrease in the brain-to-body weight ratio observed in this report is probably of little importance.

The slight decrease in the contents of cholesterol and phospholipids of the cerebral cortex after exposure to PCE might indicate a loss of lipids. Of the other solvents we have investigated, only toluene has resulted in a decrease in phospholipids (13). The importance of changes in the brain lipid class composition after exposure to PCE has to be further investigated.

After exposure to PCE, an increase in the proportion of long-chain PUFA 22:5 (N-6) and 22:6 $(\mathrm{N}-3)$ at the expense of stearic acid was observed. These two fatty acids are the end products of the desaturation and elongation sequences of the two essential fatty-acid families, the linoleic acid series $(\mathrm{N}-6)$ and the linolenic acid series $(\mathrm{N}-3)$. The general increase in the 22-carbon fatty acids of both the $\mathrm{N}-6$ and $\mathrm{N}-3$ series would suggest an increased desaturation and elongation of the last steps in the sequence of their syntheses. Such a conclusion is in agreement with that of our previous study on gerbils (14). However in the present study only the metabolic end products, PUFA, were significantly changed. This finding contrasts with those of our previous study (14), in which some of the intermediate PUFA were also affected.

The other two solvents in this study, 1,1,1-TCE and Freon 11, had no effects on the animals. An explanation for this different behavior of the solvents might be the very low uptake of freons in blood (2) and the relatively low uptake and solubility of 1,1,1-trichloroethane in blood $(1,6)$. Another explanation could be that the chloroethylenes specifically interact with the enzyme systems which regulate desaturation and elongation.

Changes in the membrane lipid and fatty-acid composition after the exposure of animals to anesthetics and related compounds, such as organic solvents, have often been attributed a compensatory role for the increased fluidity or disturbed packing of membrane lipids which results from the introduction of foreign lipophilic molecules into the membrane (7). The changes in the fatty-acid pattern observed after exposure to PCE in this study did not fit directly into any of the common hypotheses for membrane adaptation. However, in view of the complex behavior of anesthetics on membranes (5), the possibility that a compensatory mechanism was responsible for the observed changes in the fatty-acid pattern cannot be completely excluded.

From this and from previous studies regarding $x y-$ lene and toluene (13), it appears that $30 \mathrm{~d}$ of continuous exposure of rats to organic solvents at a moderate concentration ( $320 \mathrm{ppm})$ is suitable for the screening of lipid changes in the brain during such exposures. From these experiments it can be concluded that some of the solvents investigated (xylene, Freon 11, and 1,1,1-trichloroethane) had little or no effect on the brain lipid or fatty-acid composition. Other solvents like toluene and the chloroethylenes had specific effects related to the compound. No general solvent effects could be observed. These findings stress the importance of knowledge about the specific toxic effects of various solvents which are often present together as mixtures during commercial and household use.

\section{Acknowledgments}

This work was supported by grants from the Swedish Work Environment Fund (85-0505, 86-0182, 87-0202). We thank Ms G Grönstedt for typing the manuscript.

\section{References}

1. Åstrand I. Uptake of solvents in the blood and tissues of man: A review. Scand J Work Environ Health 1 (1975) 199-218.

2. Andersen ME, Gargas ML, Jones RA, Jenkins LJ Jr. Determination of the kinetic constants for metabolism of inhaled toxicants in vivo using gas uptake measurements. Toxicol Appl Pharmacol 54 (1980) 100-116.

3. Bartlett GR. Phosphorous assay in column chromatography. J Biol Chem 243 (1959) 466-468.

4. Franey RJ, Amador E. Serum cholesterol measurement based on ethanol extraction and ferric chloride-sulfuric acid. Clin Chim Acta 21 (1968) 255-263.

5. Hizemann RJ, Schueler HE, Graham Britain C, Kreishman GP. Ethanol-induced changes in neuronal membrane order: An NMR study. Biochim Biophys Acta 859 (1986) 189-197.

6. Holmberg B, Jakobson I, Sigvardsson K. A study on the distribution of methylchloroform and n-octane in the mouse during and after inhalation. Scand J Work Environ Health 3 (1977) 43-52.

7. Janoff AS, Miller KW. A critical assessment of the lipid theories of general anaesthetic action. In: Chapman D, ed. Biological membranes. Volume 4. Academic Press, New York, NY 1982, pp 417-477.

8. Kjellstrand P, Lanke J, Bjerkemo J, Zetterqvist L, Månsson L. Irreversible effects of trichloroethylene exposure on the central nervous system. Scand J Work Environ Health 6 (1980) 40-47.

9. Kyrklund T. Two procedures to remove polar contaminants from a crude brain lipid extract by using prepacked reversed-phase columns. Lipids (in press).

10. Kyrklund $T$, Alling $C$, Kjellstrand $P$, Haglid KG. Chronic effects of perchloroethylene on the composition of lipid and acyl groups in the cerebral cortex and 
hippocampus of the gerbil. Toxicol Lett 22 (1984) 343349.

11. Kyrklund T, Alling C, Kjellstrand P, Haglid K. Fatty acid composition of ethanolamine phosphoglycerides in different areas of the gerbil brain after chronic exposure to trichloroethylene. Neurochem Pathol 3 (1985) $151-158$.

12. Kyrklund $\mathbf{T}$, Kjellstrand $\mathbf{P}$, Haglid KG. Fatty acid changes in rat brain ethanolamine phosphoglycerides during and following chronic exposure to trichloroethylene. Toxicol Appl Pharmacol 85 (1986) 145-153.

13. Kyrklund T, Kjellstrand P, Haglid K. Brain lipid changes in rats exposed to xylene and toluene. Toxicology 45 (1987) $123-133$.

14. Kyrklund T, Kjellstrand P, Haglid KG. Lipid composition and fatty acid pattern of the gerbil brain after exposure to perchloroethylene. Arch Toxicol 60 (1987) $397-400$.

15. Svennerholm L. Distribution and fatty acid composition of phosphoglycerides in normal human brain. $J$ Lipid Res 9 (1968) 570—579.

Received for publication: 22 February 1988 